\title{
Restless leg syndrome, sleep quality and fatigue in multiple sclerosis patients
}

\author{
N.C.V. Moreira, R.S. Damasceno, C.A.M. Medeiros, P.F.C. de Bruin, C.A.C. Teixeira, \\ W.G. Horta and V.M.S. de Bruin \\ Departamento de Medicina, Universidade Federal do Ceará, Fortaleza, CE, Brasil \\ Correspondence to: V.M.S. de Bruin, Departamento de Medicina, Universidade Federal do Ceará, \\ Rua Prof. Costa Mendes, 1608, 4ํandar, 60430-040 Fortaleza, CE, Brasil \\ Fax: +55-85-3261-5540. E-mail: veralicebruin@gmail.com
}

\begin{abstract}
We have tested the hypothesis that restless leg syndrome (RLS) is related to quality of sleep, fatigue and clinical disability in multiple sclerosis (MS). The diagnosis of RLS used the four minimum criteria defined by the International Restless Legs Syndrome Study Group. Fatigue was assessed by the Fatigue Severity Scale (FSS >27), quality of sleep by the Pittsburgh Sleep Quality Index (PSQI >6), excessive daytime sleepiness by the Epworth Sleepiness Scale $(E S S>10)$ and clinical disability by the Expanded Disability Status Scale (EDSS). Forty-four patients (32 women) aged 14 to 64 years (43 \pm 14 ) with disease from 0.4 to 23 years $(6.7 \pm 5.9)$ were evaluated. Thirty-five were classified as relapsing-remitting, 5 as primary progressive and 4 as secondary progressive. EDSS varied from 0 to 8.0 (3.6 \pm 2.0$)$. RLS was detected in 12 cases (27\%). Patients with RLS presented greater disability $(P=0.01)$, poorer sleep $(P=0.02)$ and greater levels of fatigue $(P=0.03)$. Impaired sleep was present in 23 $(52 \%)$ and excessive daytime sleepiness in 3 cases (6.8\%). Fatigue was present in 32 subjects (73\%) and was associated with clinical disability $(P=0.000)$ and sleep quality $(P=0.002)$. Age, gender, disease duration, MS pattern, excessive daytime sleepiness and the presence of upper motor neuron signs were not associated with the presence of RLS. Fatigue was best explained by clinical disability and poor sleep quality. Awareness of RLS among health care professionals may contribute to improvement in MS management.
\end{abstract}

Key words: Restless leg syndrome; Multiple sclerosis; Sleep; Fatigue; Pittsburgh Sleep Quality Index

Presented at the XI Congresso Brasileiro do Sono, Fortaleza, CE, Brazil, November 11-14, 2007.

Research partially supported by MCT-CNPq (\#306468/2006-9).

Received November 6, 2007. Accepted October 21, 2008

\section{Introduction}

The clinical spectrum of multiple sclerosis (MS) has changed over the past few years due to new diseasemodifying therapies (1). However, several symptoms may have serious implications for patient disability. Sleep disturbance, fatigue and depressive symptoms are frequently described in association with impaired quality of life $(2,3)$. Fatigue is still one of the most common and disabling symptoms of MS patients affecting as many as $70 \%$ in some studies $(4,5)$. Controversy remains over the causes of fatigue in MS and attempts have been made to correlate fatigue with clinical disability, disease progression and immunological markers $(6,7)$.

Restless leg syndrome (RLS) is an important cause of sleep disruption and disability in several clinical and neurological disorders and can be identified on the basis of clinical criteria (8). Complaints of unpleasant sensation deep inside the legs, occurring at rest, particularly at bedtime, accompanied by an irresistible urge to move the limbs producing a temporary relief of symptoms, are sufficient to identify RLS. Recently, RLS has been described to be common in MS $(9,10)$. However, the relationship between RLS and sleep quality, fatigue and clinical disability in MS patients has not been fully investigated. Moreover, the contribution of clinical factors to the presence of RLS 
has yet to be clarified.

In the present study, we hypothesized that RLS is frequent and related to quality of sleep, fatigue and clinical disability in MS patients.

\section{Patients and Methods}

\section{Patients}

Fifty consecutive patients with MS, below the age of 64 years, regardless of disease duration, regularly attending an MS outpatient clinic were initially recruited for the study. Six subjects were excluded due to uncertainty of diagnosis $(\mathrm{N}=3)$, recent infectious illness $(\mathrm{N}=2)$, or unwillingness to participate $(\mathrm{N}=1)$. Thus, the total number of patients in the study was 44 . The study protocol was approved by the University Research Ethics Committee and written informed consent was obtained for all patients.

\section{Study design}

This was a cross-sectional study of patients with a clinical diagnosis of MS. Demographic and clinical data were recorded using a closed-question, data collection instrument. All cases were investigated while clinically stable, i.e., absence of exacerbated infectious disease, traumatic or other acute complication in the previous 3 months as assessed by history and review of medical records. Neurological examination was performed by one of the investigators. All variables were measured concurrently.

\section{Assessment procedures}

RLS was established using the minimum criteria defined by the International Restless Legs Syndrome Study Group: 1) an urge to move the legs, usually accompanied or caused by uncomfortable and unpleasant sensations in the legs; 2) the urge to move or unpleasant sensations begin or worsen during periods of rest or inactivity, such as lying or sitting; 3 ) the urge to move or unpleasant sensations are partially or totally relieved by movement, such as walking or stretching, at least as long as the activity continues, and 4) the urge to move or unpleasant sensations are worse in the evening or night than during the day or only occur in the evening or night (11).

Sleep quality was evaluated by the Pittsburgh Sleep Quality Index (PSQI). This scale has seven components, each one dealing with a major aspect of sleep: 1) subjective quality of sleep, 2) sleep onset latency, 3) sleep duration, 4) sleep efficiency, 5) presence of sleep disturbances, 6) use of hypnotic-sedative medication, and 7) presence of daytime disturbances, as an indication of daytime alertness. Individuals with a total PSQI score of 6 or more were considered to be poor sleepers (12).

Daytime somnolence was assessed by the Epworth Sleepiness Scale (ESS). This is a validated questionnaire containing eight items that ask about the expectation of dozing in eight hypothetical situations. Dozing probability ratings range from 0 (no probability) to 3 (high probability). ESS score of 10 or more indicates excessive daytime sleepiness (13).

Fatigue was assessed by the Fatigue Severity Scale (FSS) (14), a self-report questionnaire composed by nine items. Each item scores on a seven-point scale ranging from 1 (meaning absence of fatigue) to 7 (high level of fatigue). Patients presenting scores greater than 27 were diagnosed as having fatigue.

The type of MS was classified as relapsing-remitting, primary progressive and secondary progressive. All cases were classified as having spasticity or not and/or other upper motor neuron signs involving lower extremities. Disease severity was evaluated by the Expanded Disability Status Scale (EDSS). The scale provides a score between 0 (meaning very little disability and a normal neurological examination) to a maximum of 10 (meaning death due to MS) (15).

Results of complete blood count, electrolyte levels, renal function, and medication in the last 30 days was obtained from medical records. Body mass index was calculated as the ratio between weight $(\mathrm{kg})$ and squared height $\left(\mathrm{m}^{2}\right)$. Anemia (hemoglobin level $<12.0 \mathrm{~g} / \mathrm{dL}$ ) or iron deficiency was not present in any patient.

\section{Statistical analysis}

For statistical analysis and data description, patients were stratified according to the presence or absence of RLS. Data were examined for normality using the ShapiroWilk test and for homogeneity of variance with the Levene test. Comparisons between variables were performed using the chi-square test for categorical data, ANOVA and the Mann-Whitney test for parametric and non-parametric data, respectively. To examine the association between RLS and upper motor neuron signs, logistic regression was used to calculate the odds ratios (OR). Multiple logistic regression analysis was conducted in a stepwise manner. Data were analyzed using a Statistic Package for Social Sciences (SPSS-Norusis, 1993) software for Windows. Statistical significance was defined at the $95 \%$ level $(P<$ 0.05).

\section{Results}

Patient characteristics are reported in Table 1. Patients were mostly female $(\mathrm{N}=32 ; 73 \%)$, with an age range from 
14 to 64 years ( $43 \pm 14$ ) and disease duration from 1 to 23 years $(6.8 \pm 5.9)$. The majority of the patients were classified as having the relapsing-remitting form ( $N=35,80 \%)$, followed by primary progressive $(\mathrm{N}=5,11 \%)$ and secondary progressive $(\mathrm{N}=4,9.0 \%)$. Twelve subjects $(27 \%)$ fulfilled the clinical criteria for the presence of RLS. Subjects grouped according to the presence/absence of RLS were found to have the relapsing-remitting (11/24), the primary progressive (1/3) and the secondary progressive $(0 / 5)$ form, which was not different between groups. Age, gender and disease duration were not different between groups (Table 1). Age at onset of RLS symptoms varied from 30 to 64 years $(48 \pm 15.8)$. All patients with RLS symptoms reported that they began after the start of the MS symptoms. The manifestation of spasticity (73\%) and/ or other upper motor neuron signs (83\%) was not associated with the presence of $\mathrm{RLS}(\mathrm{P}=0.32$; OR $=0.49 ; \mathrm{Cl}=$ 0.088-2.76).

Poor sleep quality was found in 23 cases (52\%). Patients with RLS presented higher scores for sleep latency, and lower scores for sleep duration and sleep efficiency (Figure 1). Fatigue was present in 32 subjects (73\%) and was associated with clinical disability as evaluated by the EDSS $(P=0.000)$, with sleep quality $(P=0.002)$ and at a lesser degree with the presence of RLS $(P=0.02$; Table 2$)$. The association between fatigue and sleep quality was significant after controlling for clinical disability, as evaluated by the EDSS $(P=0.03)$. Excessive daytime sleepiness was detected in only 3 subjects $(7 \%)$ and was not associated with any of the parameters studied.

Hemoglobin levels (range 11.4 to $14.3 \mathrm{~g} / \mathrm{dL}$ ) were not different between patients with or without RLS. Glucose (range from 70 and $120 \mathrm{mg} / \mathrm{dL}$ ), cholesterol (range from 140 to $230 \mathrm{mg} / \mathrm{dL}$ ) and creatinine (range 0.5 to $1.1 \mathrm{mg} / \mathrm{dL}$ ) levels were within expected normal range and not different between the two groups.

\section{Discussion}

This study showed that RLS is common in MS and related to poor sleep quality, fatigue and clinical disability. Patients with RLS showed worse scores in several sleep domains such as sleep latency, sleep efficiency and sleep duration. Furthermore, as previously described, sleep quality was associated with fatigue (16) making a stronger case for treating RLS. Fatigue, a severe and debilitating symptom in MS, was best explained by clinical disability, confirming previous data (17) followed by quality of sleep.

Previously, two studies described RLS in association with MS with a reported prevalence of $32-37 \%(9,10)$. However, there was no mention of an association among
RLS, sleep quality and fatigue in those reports. Despite the relatively small number of patients involved in the present study, RLS was also found to be present in approximately one-third of the patients. Epidemiological surveys based

Table 1. Characteristics of 44 patients with multiple sclerosis with or without restless leg syndrome.

\begin{tabular}{|c|c|c|}
\hline Characteristics & $\begin{array}{l}\text { Without RLS } \\
\qquad(\mathrm{N}=32)\end{array}$ & $\begin{array}{l}\text { With RLS } \\
(N=12)\end{array}$ \\
\hline Gender (female/male) & $24 / 8$ & $8 / 4$ \\
\hline \multicolumn{3}{|l|}{ Age (years) } \\
\hline Range & $14-64$ & 18-61 \\
\hline Mean \pm SD & $44.1 \pm 13.4$ & $40.7 \pm 14.8$ \\
\hline \multicolumn{3}{|c|}{ Disease duration (years) } \\
\hline Range & $1-23$ & $1-23$ \\
\hline Mean $\pm S D$ & $7.3 \pm 5.8$ & $5.6 \pm 6.1$ \\
\hline \multicolumn{3}{|l|}{ EDSS } \\
\hline Range & $0-8$ & $2-6.5$ \\
\hline Mean $\pm S D$ & $3.2 \pm 2.0$ & $4.8 \pm 1.4^{*}$ \\
\hline \multicolumn{3}{|l|}{ FSS score } \\
\hline Range & $12-63$ & 19-63 \\
\hline Mean \pm SD & $39.9 \pm 17.1$ & $50.0 \pm 13.4^{*}$ \\
\hline \multicolumn{3}{|l|}{ PSQI score } \\
\hline Range & $0-15$ & $2-17$ \\
\hline Mean \pm SD & $6.3 \pm 3.9$ & $9.0 \pm 5.5^{*}$ \\
\hline \multicolumn{3}{|l|}{ ESS score } \\
\hline Range & $2-16$ & $0-15$ \\
\hline Mean $\pm S D$ & $5.7 \pm 3.0$ & $5.7 \pm 4.0$ \\
\hline
\end{tabular}

Data are reported as range and mean $\pm \mathrm{SD}$. RLS = restless leg syndrome; EDSS = Expanded Disability Status Scale; FSS = Fatigue Severity Scale; PSQI = Pittsburgh Sleep Quality Index; ESS = Epworth Sleepiness Scale $.{ }^{*} P<0.05$ compared to without RLS (chi-square test and Mann-Whitney test).

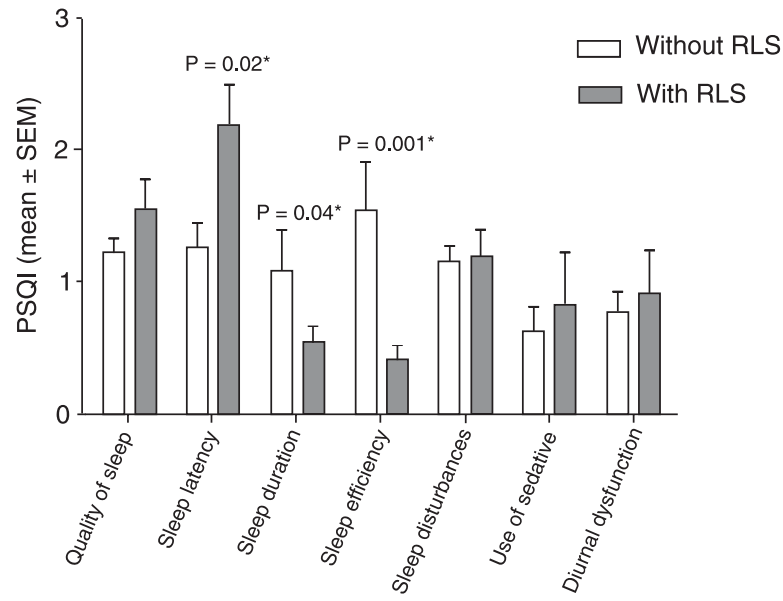

Figure 1. Sleep dimensions as assessed by the Pittsburgh Sleep Quality Index (PSQI) in multiple sclerosis patients with $(N=12)$ and without $(\mathrm{N}=32)$ restless leg syndrome $(\mathrm{RLS})$. The MannWhitney test was used for statistical comparisons. 
on primary care patients have initially shown a prevalence of RLS ranging from 5 to $15 \%$ in Caucasians (18-21). Recently, larger population-based studies have reported lower incidences oscillating from $2-3 \%(22,23), 5-$ $7 \%(24,25)$ to a maximum of $12 \%(26)$. RLS prevalence has been reported to be higher in female patients in most reports $(24,25)$ and to increase with age (19). Ethnic variations have been described and lower prevalence rates have been claimed in Greeks (27). A recent population-based study has shown a prevalence of $7.1 \%$ among Brazilians (28). It has been reported that considering the fact that MS patients are usually young, the presence of RLS in these individuals makes the finding more significant (9). However, age was not significantly different between patients with and without RLS. In the present study, the majority of cases were the relapsing remitting clinical form, confirming that, despite being less frequent in the tropics, the clinical phenotype and genetic component are generally similar to subtropic populations (29).

The pathogenesis of RLS has been connected with a genetic cause (30), iron deficiency (31), dopamine involvement (32), peripheral neuropathy, and diabetes (33). It has also been claimed that more than one pathological process may be involved (34). Given the fact that MS is sometimes a disease of precise neurological localization, attempts to establish a connection between spinal cord lesion and RLS symptoms have been made without success (35). More recently, cervical cord lesion has been associated with the presence of RLS suggesting that MS is actually a cause of secondary RLS (36). According to our data, no association was found between upper motor neuron involvement and the presence of RLS. We also confirm previous reports showing no association between anemia or iron deficiency with RLS in MS patients $(9,10)$.

A number of patients with RLS also have periodic limb movements during sleep (PLMS), defined as stereotyped, periodic, jerking movements, typically consisting of flexion of the ankle, knee, and hip. Generally, PLMS have been found in approximately $80-90 \%$ of patients with $\operatorname{RLS}(37,38)$ and previously, PLMS was associated with sleep disruption in MS (39). Neurophysiological examination, such as polysomnography, is essential for the diagnosis of PLMS and can contribute to diagnosis in uncertain RLS cases. PLMS are sometimes accompanied by arousals leading to sleep fragmentation and excessive daytime sleepiness. Disturbances in initiating and maintaining sleep, sleepiness and less refreshing sleep can be associated with PLMS and with RLS and the importance of identifying factors contributing to fatigue and poor sleep quality in MS cannot be minimized. Moreover, response of RLS symptoms and fatigue to treatment with dopaminergic agents might have a major impact on daily symptoms and quality of life in these patients.

We confirm that RLS is frequent in MS and associated with poor sleep quality and fatigue. Despite the fact that symptomatic treatment for RLS is available, it is still an under-recognized condition and frequently MS patients remain undiagnosed and untreated. RLS has a negative impact on sleep, quality of life and cognitive functions and higher awareness of RLS among physicians is warranted.

\section{References}

1. Boissy A, Fox RJ. Current treatment options in multiple sclerosis. Curr Treat Options Neurol 2007; 9: 176-186.

2. Lobentanz IS, Asenbaum S, Vass K, Sauter C, Klosch G, Kollegger $\mathrm{H}$, et al. Factors influencing quality of life in multiple sclerosis patients: disability, depressive mood, fatigue and sleep quality. Acta Neurol Scand 2004; 110: 6-13.
3. Kaynak H, Altintas A, Kaynak D, Uyanik O, Saip S, Agaoglu $\mathrm{J}$, et al. Fatigue and sleep disturbance in multiple sclerosis. Eur J Neurol 2006; 13: 1333-1339.

4. Tola MA, Yugueros MI, Fernandez-Buey N, Marco J, Gutierrez-Garcia JM, Gomez-Nieto J, et al. Deficiency, disability and handicap in multiple sclerosis: a population-based 
study in Valladolid. Rev Neurol 1998; 26: 728-734.

5. Vercoulen JH, Hommes OR, Swanink CM, Jongen PJ, Fennis JF, Galama JM, et al. The measurement of fatigue in patients with multiple sclerosis. A multidimensional comparison with patients with chronic fatigue syndrome and healthy subjects. Arch Neurol 1996; 53: 642-649.

6. Strober LB, Arnett PA. An examination of four models predicting fatigue in multiple sclerosis. Arch Clin Neuropsychol 2005; 20: 631-646

7. Alarcia R, Ara JR, Martin J, Bertol V, Bestue M. Importance and factors related to chronic fatigue in multiple sclerosis. Neurologia 2005; 20: 77-84.

8. Allen RP, Picchietti D, Hening WA, Trenkwalder C, Walters AS, Montplaisi J. Restless legs syndrome: diagnostic criteria, special considerations, and epidemiology. A report from the restless legs syndrome diagnosis and epidemiology workshop at the National Institutes of Health. Sleep Med 2003; 4: 101-119.

9. Manconi M, Fabbrini M, Bonanni E, Filippi M, Rocca M, Murri L, et al. High prevalence of restless legs syndrome in multiple sclerosis. Eur J Neurol 2007; 14: 534-539.

10. Auger $C$, Montplaisir J, Duquette $P$. Increased frequency of restless legs syndrome in a French-Canadian population with multiple sclerosis. Neurology 2005; 65: 1652-1653.

11. Rochester M. Periodic limb movement disorder. In: American Sleep Disorders Association (Editor), Diagnostic Classification Steering Committee of the American Sleep Disorders Association. The International Classification of Sleep Disorders Diagnostic and Coding Manual. 1990. p 65-68.

12. Buysse DJ, Reynolds CF III, Monk TH, Berman SR, Kupfer DJ. The Pittsburgh Sleep Quality Index: a new instrument for psychiatric practice and research. Psychiatry Res 1989; 28: 193-213.

13. Johns MW. A new method for measuring daytime sleepiness: the Epworth sleepiness scale. Sleep 1991; 14: 540545.

14. Krupp LB, LaRocca NG, Muir-Nash J, Steinberg AD. The fatigue severity scale. Application to patients with multiple sclerosis and systemic lupus erythematosus. Arch Neurol 1989; 46: 1121-1123

15. Kurtzke JF. Rating neurologic impairment in multiple sclerosis: an expanded disability status scale (EDSS). Neurology 1983; 33: 1444-1452.

16. Attarian HP, Brown KM, Duntley SP, Carter JD, Cross AH. The relationship of sleep disturbances and fatigue in multiple sclerosis. Arch Neurol 2004; 61: 525-528.

17. Flachenecker $P$, Kumpfel $T$, Kallmann B, Gottschalk $M$, Grauer O, Rieckmann P, et al. Fatigue in multiple sclerosis: a comparison of different rating scales and correlation to clinical parameters. Mult Scler 2002; 8: 523-526.

18. Van De Vijver DA, Walley T, Petri H. Epidemiology of restless legs syndrome as diagnosed in UK primary care. Sleep Med 2004; 5: 435-440.

19. Hening W, Walters AS, Allen RP, Montplaisir J, Myers A, Ferini-Strambi L. Impact, diagnosis and treatment of restless legs syndrome (RLS) in a primary care population: the REST (RLS epidemiology, symptoms, and treatment) primary care study. Sleep Med 2004; 5: 237-246.

20. Dantas FG, Medeiros JL, Farias KS, Ribeiro CD. Restless legs syndrome in institutionalized elderly. Arq Neuropsiquiatr 2008; 66: 328-330.
21. Crochard A, El Hasnaoui A, Pouchain D, Huas D, Arnulf I, Krieger J, et al. Diagnostic indicators of restless legs syndrome in primary care consultations: the DESYR study. Mov Disord 2007; 22: 791-797.

22. Picchietti D, Allen RP, Walters AS, Davidson JE, Myers A, Ferini-Strambi L. Restless legs syndrome: prevalence and impact in children and adolescents - the Peds REST study. Pediatrics 2007; 120: 253-266.

23. Phillips B, Young T, Finn L, Asher K, Hening WA, Purvis C. Epidemiology of restless legs symptoms in adults. Arch Intern Med 2000; 160: 2137-2141.

24. Ohayon MM, Roth T. Prevalence of restless legs syndrome and periodic limb movement disorder in the general population. J Psychosom Res 2002; 53: 547-554.

25. Rijsman R, Neven AK, Graffelman W, Kemp B, de Weerd A. Epidemiology of restless legs in The Netherlands. Eur $J$ Neurol 2004; 11: 607-611.

26. Wali SO, Krayem AB, Samman YS, Mirdad S, Alshimemeri AA, Almobaireek A. Sleep disorders in Saudi health care workers. Ann Saudi Med 1999; 19: 406-409.

27. Hadjigeorgiou GM, Stefanidis I, Dardiotis E, Aggellakis K, Sakkas GK, Xiromerisiou G, et al. Low RLS prevalence and awareness in central Greece: an epidemiological survey. Eur J Neurol 2007; 14: 1275-1280.

28. Eckeli AL, Gitai L, Dach F, Sander H, Passos AD, Prado GF, et al. Restless legs syndrome - a community-based study of prevalence in Brazil. Sleep 2008; 31 (Abstract Supplement): A272.

29. Palacio LG, Rivera D, Builes JJ, Jimenez ME, Salgar M, Anaya JM, et al. Multiple sclerosis in the tropics: genetic association to STR's loci spanning the HLA and TNF. Mult Scler 2002; 8: 249-255.

30. Birinyi PV, Allen RP, Hening W, Washburn T, Lesage S, Earley CJ. Undiagnosed individuals with first-degree relatives with restless legs syndrome have increased periodic limb movements. Sleep Med 2006; 7: 480-485.

31. Mizuno S, Mihara T, Miyaoka T, Inagaki T, Horiguchi J. CSF iron, ferritin and transferrin levels in restless legs syndrome. J Sleep Res 2005; 14: 43-47.

32. Braga-Neto P, da Silva-Junior FP, Sueli MF, de Bruin PF, de Bruin V. Snoring and excessive daytime sleepiness in Parkinson's disease. J Neurol Sci 2004; 217: 41-45.

33. Lopes LA, Lins CM, Adeodato VG, Quental DP, de Bruin $\mathrm{PF}$, Montenegro RM Jr, et al. Restless legs syndrome and quality of sleep in type 2 diabetes. Diabetes Care 2005; 28 : 2633-2636.

34. Whittom S, Dauvilliers $\mathrm{Y}$, Pennestri MH, Vercauteren F, Molinari N, Petit $D$, et al. Age-at-onset in restless legs syndrome: a clinical and polysomnographic study. Sleep Med 2007; 9: 54-59.

35. Gomez-Choco MJ, Iranzo A, Blanco Y, Graus F, Santamaria J, Saiz A. Prevalence of restless legs syndrome and REM sleep behavior disorder in multiple sclerosis. Mult Scler 2007; 13: 805-808.

36. Manconi M, Rocca MA, Ferini-Strambi L, Tortorella $P$, Agosta F, Comi G, et al. Restless legs syndrome is a common finding in multiple sclerosis and correlates with cervical cord damage. Mult Scler 2008; 14: 86-93.

37. Montplaisir J, Boucher S, Poirier G, Lavigne G, Lapierre O, Lesperance $P$. Clinical, polysomnographic, and genetic characteristics of restless legs syndrome: a study of 133 
patients diagnosed with new standard criteria. Mov Disord 1997; 12: 61-65.

38. Michaud M, Paquet J, Lavigne G, Desautels A, Montplaisir J. Sleep laboratory diagnosis of restless legs syndrome. Eur Neurol 2002; 48: 108-113.
39. Ferini-Strambi L, Filippi M, Martinelli $V$, Oldani A, Rovaris M, Zucconi M, et al. Nocturnal sleep study in multiple sclerosis: correlations with clinical and brain magnetic resonance imaging findings. J Neurol Sci 1994; 125: 194-197. 